\title{
A UTOMATIC SYSTEM FOR lOCALIZATION AND RECOGNITION OF VEHICLE PLATE NUMBERS
}

\author{
N. Vázquez, M. Nakano \& H. Pérez-Meana \\ Graduate and Research Section Mechanical and Electrical School, \\ Culhuacán Campus National Polytechnic Institute of Mexico \\ Av. Santa Ana No. 1000, San Francisco Culhuacán, 4430 México D. F. México \\ E-mails: ntecpanecatl@hotmail.com; hmpm@calmecac.esimecu.ipn.mx, hmpm@prodigy.net.mx \\ Received: April $18^{\text {th }} 2001$ and accepted March $6^{\text {th }} 2002$
}

\section{ABSTRACT}

This paper proposes a vehicle numbers plate identification system, which extracts the charactersfeaturesofa plate from a captured image by a digital camera. Then identify the symbols of the number plate using a multilayer neural network. The proposed recognition system consists of two processes: The training process and the recognition process. During the training process, a database is created using 310 vehicular plate images. Then using this database a multilayer neural network is trained to identify the symbolsin the vehicles plate. While the recognition process consists of four stages: The number plate localization stage, the binarization stage, the segmentation stage and the recognition stage which uses the previously trained multilayer neural network. The performance of proposed system is evaluated using more than 1200 symbols from the 310 captured images. The simulation results show that approximately $91.5 \%$ of the 310 plate images in the vehicle have been correctly located. The proposed system performance, regarding the identification of numbers and letters in the plate, was evaluated separately. Here the recognition rate is $95.55 \%$ and $91.6 \%$, respectively. So the global recognition rate of the vehicle number plate becomesapproximately $91.2 \%$. Then from the simulation results it follows that the proposed system works fairly well and then it may be applied in the solution of several practical problems that require automatic number plate identification.

\section{RESUMEN}

Se propone un sistema de identificación de placas vehiculares que facilite y agilice la identificación de las mismas a través de redes neuronales, una vez que han sido obtenidas las características de la placa por medio de una imagen tomada con una cámara fotográfica digital. El sistema propuesto consiste de dos procesos: El proceso de entrenamiento y el proceso de reconocimiento. El proceso de reconocimiento consiste en la localización de la placa dentro de la imagen capturada, la binarización de la misma, la segmentación de los símbolos por medio de la técnica de etiquetamiento, la codificación de los símbolos segmentados y el reconocimiento de los mismos usando las redes neuronales previamente entrenadasporel proceso de entrenamiento. El proceso de entrenamiento por su parte consiste de la creación de la base de datos y el entrenamiento de las redes neuronales multicapas. El funcionamiento del sistema global se evaluó usando el porcentaje de acierto de reconocimiento de los símbolos (números y letras) de lasplacas correspondientes a 310 imágenes capturadas. Los resultados obtenidos muestran que aproximadamente en un $91.5 \%$ de las imágenes se han localizado correctamente la posición de la placa. Porsu parte el porøentaje de acierto en el reconocimiento de los dígitos y letras en la placa, se estimaron separadamente, obteniéndose porcentaje de reconocimiento de aproximadamente $95.5 \%$ y $91.6 \%$ respectivamente, mientras que el reconocimiento global de las placas consistentes de 3 números y 3 letras es de $91.2 \%$. De los resultados obtenidos podemos concluir que el sistema propuesto funciona acertadamente y podría ser empleado en diversos sistemas que requieran detección automática de placas.

KEYWORDS: Alphabet recognition, Number plate, Identification with neural networks. 


\section{INTRODUCTION}

Several practical applications require the automatic vehicles plate detection and recognition, such as: Vehicle access control to restricted places, parking billing, stolen vehicle detection, among others. Among them, the detection of stolen vehicles is very important because of the large number of stolen vehicles in many cities around the w ord. Thus the detection of stolen vehicles can be done inan efficient manner by using monitoring systems that may be located in the highw ays. This suggests the necessity of developing identification and recognition systems that could allow a fast and efficient identification of stolen vehicles, as w ell as the identification of those that may be involved in some unlaw ful actions. To illustrate the importance of this application, figure 1 show $s$ the stolen vehicles index in Mexico Oly betw een 1993 and 2001, according to Mexico City Attorney Office [1].

The fact that the number of stolen vehicles be so large, as show $\mathrm{n}$ in figure 1 , and that the number of recovered vehicles by so few, suggest the necessity of developing high performance vehicle plate recognition allow ing a faster localization and identification of stolen vehicles. The automatic identification of stolen vehicles by using fuzzy logic and neural netw orks based identification systems [2]-[4] have been an active research topic in recent years, because they allow important reduction of both, the computation time and the identification error [5]-[8]. Several other vehicle plate identification systems have been proposed using the Hough transform [9], [10] and vector quantization [3]. However theany of them are still enough reliable, or provides a high enough recognition average for practical applications.

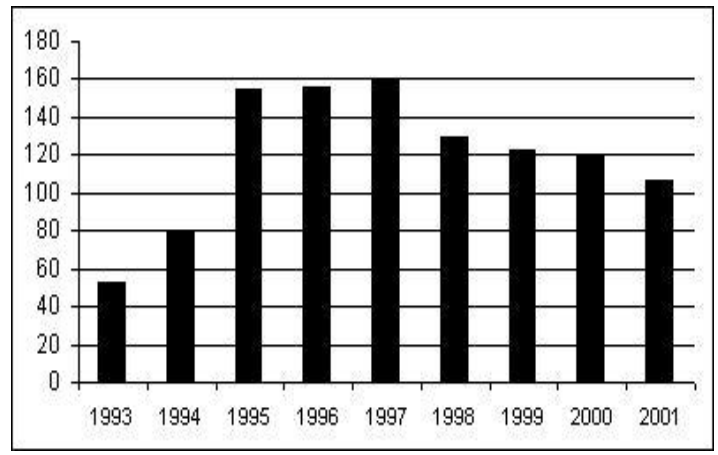

Figure 1. Average of vehicles stolen in Mexico between 1993 and 2001.

To contribute to improve the automatic vehicle plate identification systems, this paper presents a recognition method in w hich the vehicle plate image is obtained by using a digital camera. Nexttheplate image is processed to extract the plate characters such as numbers and letters, used for identification. To this end it is necessary to take in account several facts such as: The plate location w ithin the vehicle image, the plate illumination, the distance betw een the vehicle and the camera, w eather conditions, etc. To reduce these effects, the vehicles plate picture is taken and the numbers and letters in them are extracted and coded in such a way that the extracted features have low s sensitivity to the above mentioned factors. Subsequently the coded features are feed to a recognition stage consisting of a multilayer neural netw ork to carried out the plate identification. Proposed system, beside stolen car identification, can also be used in several other applications such as: Control and security in parking areas, vehicular traffic measurement and planning, automatic detection of vehicle with excess speedin highw ays, and identification of vehicles in prohibit areas, etc.

\section{PROPOSED SYSTEM}

The proposed system, show $\mathrm{n}$ in figure 2, consists of two main processes: The training and the recognition processes. The training process consists, mainly of the development of database of coded character plates and the training of a multilayer neural netw ork used for identification. The recognition process, on the other hand, consists of the vehicle plate localization inside the captured vehicle image, 
vehicle plate binarization, symbol segmentation, coding of segmented symbols and character recognition using the multilayer neural netw ork, w hose parameters w ere determined during the training process.

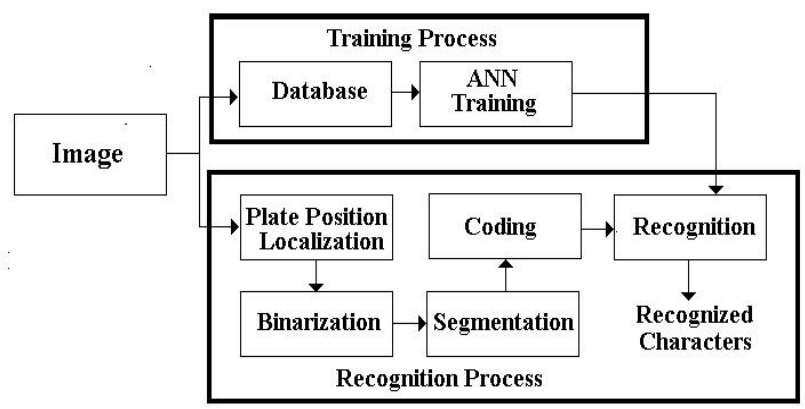

\subsection{Training process}

Figure 2. Propose vehicle plate recognition system.

During the training process a database of coded plates characters is developed which consists of 50 codes for each one of the 33 possible symbols in the plate (10 numbers and 23 letters) obtained from 250 different plate images. To this end the system show $\mathrm{n}$ in figure 3 is used. Here the symbols are extracted from the plate as show $n$ in figure 4. Next the extracted characters are converted into black and $w$ hite characters represented by using binarization. To get a more accurate binarization results, this process uses several local threshold values since the illumination of the plates, in general, is not uniform, and in most cases, the upper part has some shadow s produced by the same vehicle. The resulting black and $w$ hite characters are show $n$ in figure 5(a).

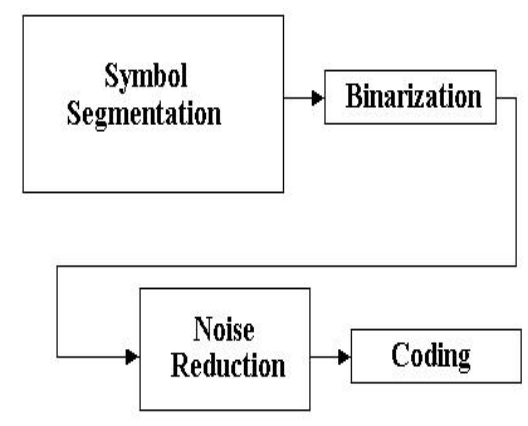

Figure 3. Database development.
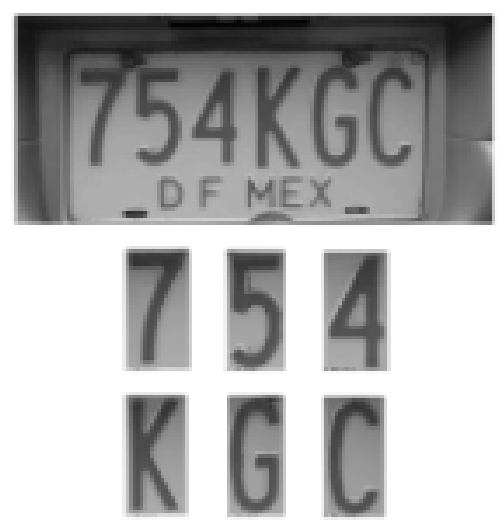

Figure 4. Segmented character and original image plate. 
Even if the threshold values w ere properly chosen, in the binarized image appear several points resulting in a noisy image. The noise in the image may be further increased by dirt and natural deterioration of the plates. There are several methods that allow s to reduce these kind of noises such as the Gaussian, low -pass and median filters, etc. How ever those methods may distort the plate characters and, when the signal to noise ratio is low, a significant amount of noise cannot be eliminated. Thus to keep the symbol shapes eliminating only the noise the labeling method is used. The resulting noise elimination in the car plates using the labeling method is show $n$ in figure 5(b), where it is show $n$ that the blackpoints in the background and the $w$ hite points inside the characters have been eliminated.
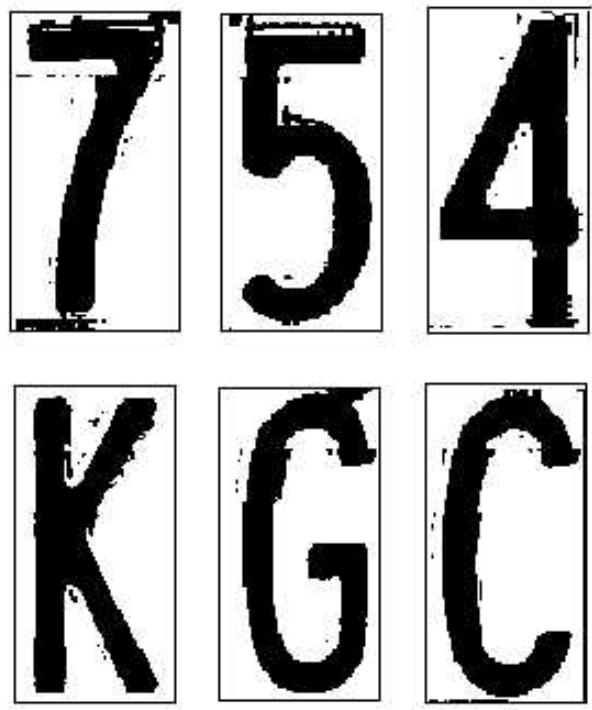

(a)

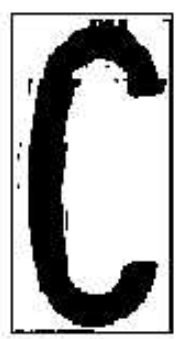

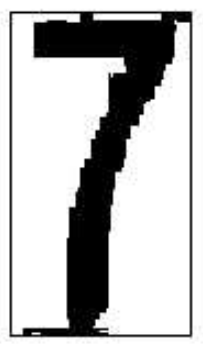
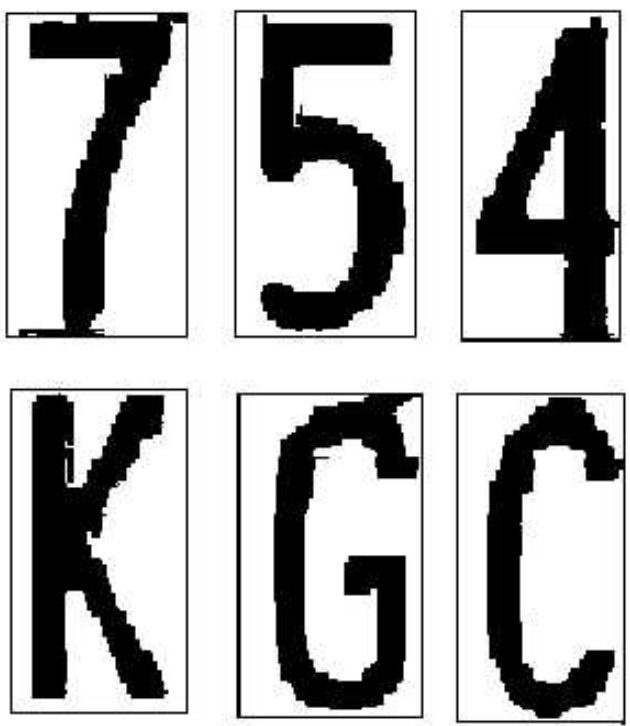

(b)

Figure 5. (a) Plates charaters after binarization process (b) Plates characteres afterthe binarizatio and noise elimination processes.

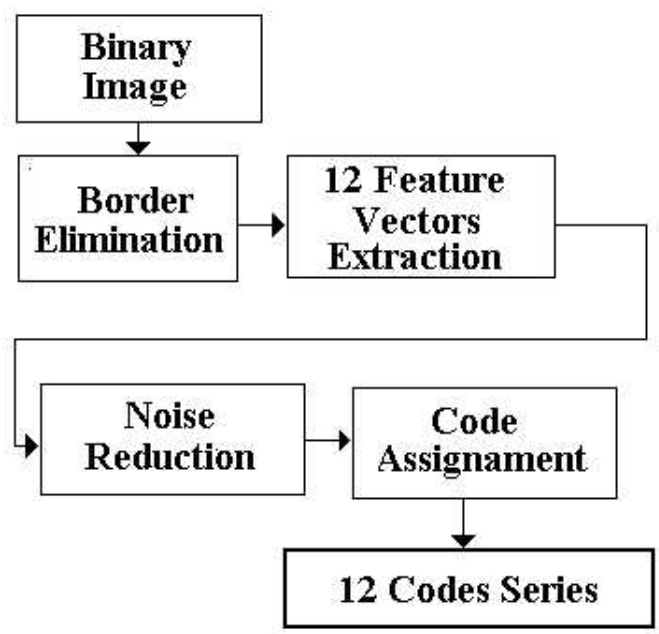

Figure 6. Coding Process

After the labeling process used to reduce the characters noise, the resulting characters are codedina similar w ay that the OCR (Optical Character Reader) [11], [12], as show $n$ in figure 6 . Here in thebinary pattern, after adjusting the image size and eliminate the $w$ hite borders, 12 horizontal lines are tracedas 
show $\mathrm{n}$ in figure 7. Each of them consisting of sequences of $w$ hite pixels (value 1) and sequences of black pixels (value 0 ), w hich generate a binary values vector. Thus for each pattern, 12 vectors are obtained. Before comparing the binary sequences $w$ ith the codebook used for assigned a code to each sequence, a noise reduction process must be done, because in general the noise introduced by the acquisition and binarization processes may introduce errors during the coding process. The noise can be easily detected measuring the length of each sequence. Then $w$ hen the length of each sequence (black or w hite) is much shorter than the symbol line w idth, the sequence (black or w hite) is considered as noise and then it is eliminated, that is if $w_{r}<w_{s} / 2$, where $w_{r}$ is the line width and $w_{s}$ is the preestablished symbol line $w$ idth. Figure 8 show $s$ the sequences of a line $w$ ith noise and the resulting line after the noise have been eliminated. Here in Figure 8(a), the second black sequence has a length of 2 pixels which is much shorter than the line symbol width, which is 20 pixels length. Thus this sequence is considered as noise and then this black sequence is changed into a white one. $h$ thesame form the third $w$ hite sequence of one pixel length is changed into a black one.

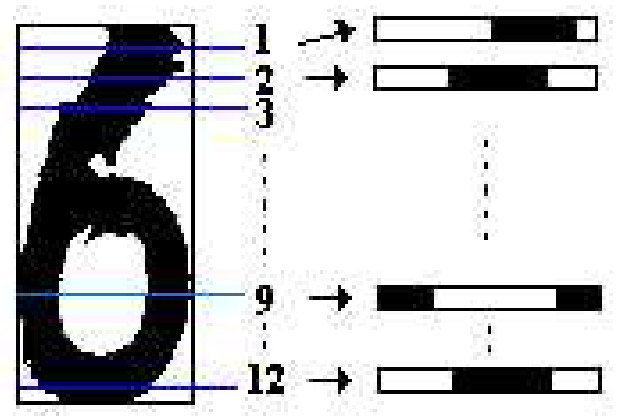

Figure 7. 12 vectors codes obtained by drawing 12 horizontal lines on the character.

(a)

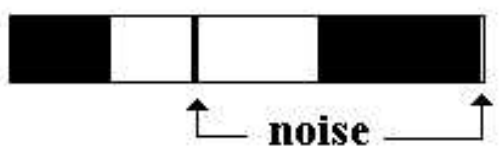

(b)

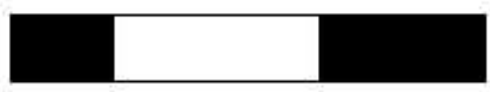

Figure 8. The principle of noise elimination process is shown (a) Line with noise (b) Line afterthe noise cancelling process is done

After the noise is cancelled, each vector generated in the previous process is compared w ith the 23 codes in the codebook show $\mathrm{n}$ in figure 9 , whose row $\mathrm{s}$ are coded corresponding to the combinations of the black-w hite sequences. Here the symbols ' $n+b+n, b+n+d$ ', etc. localized at the right hand side of each code means the combination of each sequence, where ' $n$ ' and ' $b$ ' denote black and white sequences, respectively. For instance ' $n+b+n$ ' means that the combination consists of a black, $w$ hite and black sequences respectively, and the symbols denoted as $\bar{n}$ and $\bar{b}$ mean that, in the combination, the black sequence or the w hite one has a longer length than the another ones. Thus if we look at the codebook, the codes 8 and 9 have the same sequence, how ever in the code 8 the first white sequence is longer, $w$ hile in the code 9 the longer is the second $w$ hite sequence. Thus this codification allow $s$ distinguish betw een characters with some similarities such as the 1 and 7 or $U$ and $V$. 

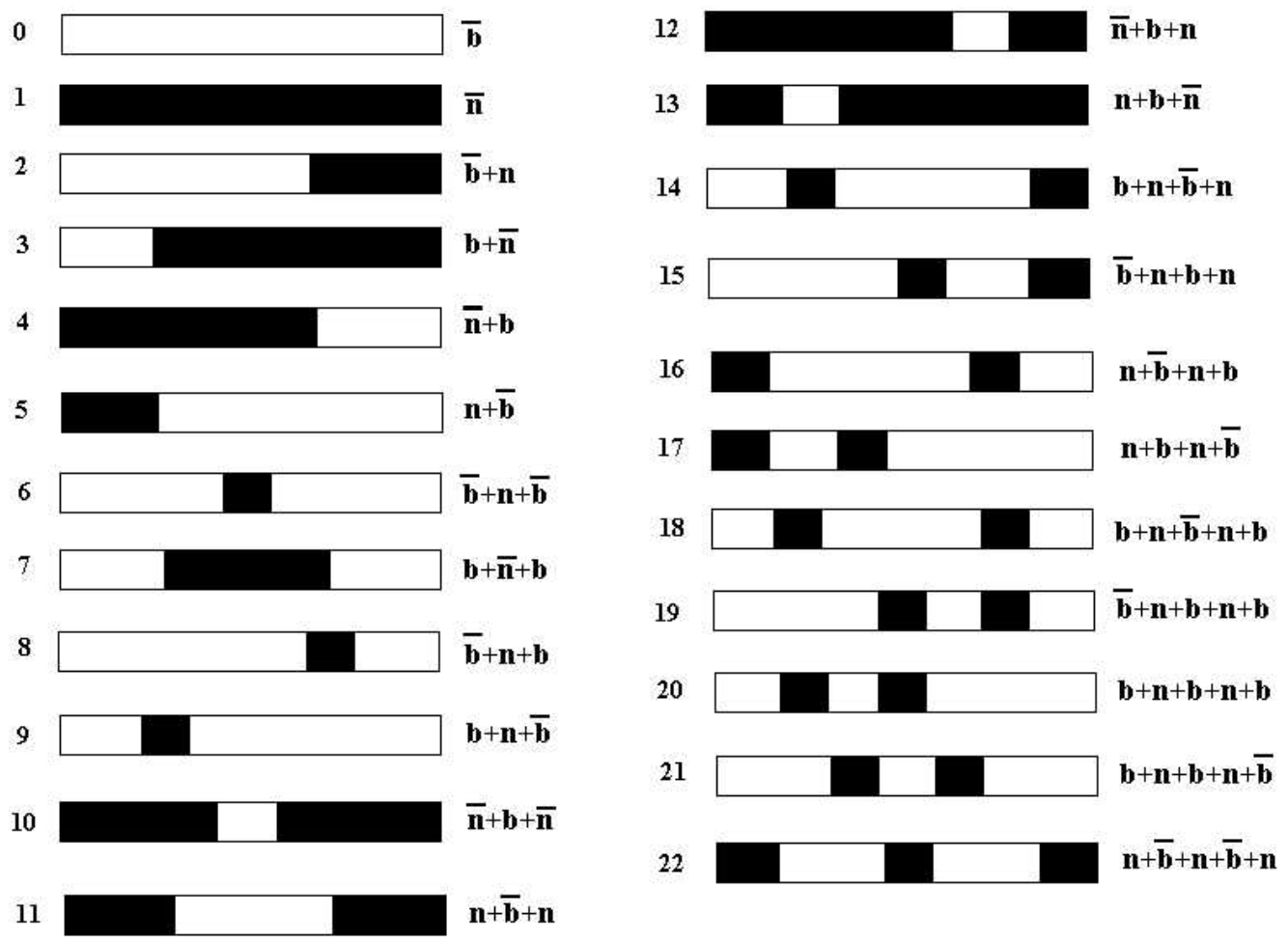

Figure 9. Codebook used for plate character coding.

Figure 10 show s 4 different patterns of symbol 7, and Table I show s the four pattern coding results. Here, we can see that the four codes are quite similar among them.

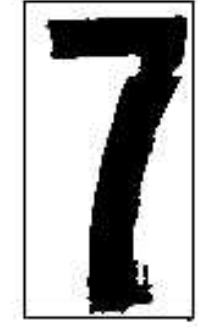

Pattern 1

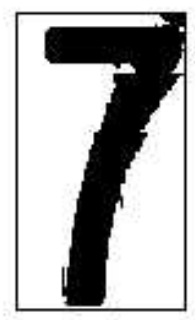

Pattern 2

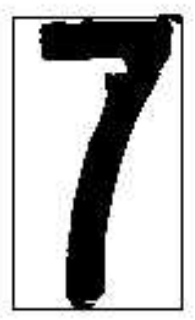

Pattern 3

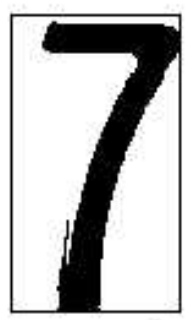

Pattern 4

Figure 10. Number 7 obtained from 4 different plates .

Table I. Code sequences obtained after applying the coding process describedabove to the 4 characters shown in figure 10. Each number corresponds to a code sequences of the codebook shown in figure

\begin{tabular}{|c|cccccccccccc|}
\hline Pattern & \multicolumn{11}{|c|}{ Codes } \\
\hline 1 & 1 & 2 & 8 & 8 & 8 & 8 & 6 & 9 & 9 & 9 & 7 & 9 \\
\hline 2 & 1 & 1 & 3 & 8 & 8 & 7 & 9 & 9 & 9 & 9 & 9 & 9 \\
\hline 3 & 1 & 1 & 8 & 8 & 8 & 6 & 9 & 9 & 9 & 9 & 9 & 9 \\
\hline 4 & 1 & 2 & 8 & 8 & 8 & 6 & 9 & 9 & 9 & 9 & 9 & 9 \\
\hline
\end{tabular}


Using the codes generated in the previous processes as training patterns, tw o multilayer perceptronare trained, one for recognize the 10 digits and the another one the 23 letters of the alphabet used in the vehicle plates. The number of neurons used in the first netw ork is: 12 neurons in the inputlayer, $10 \mathrm{in}$ the hidden layer and 10 neurons in the output one, w hile in the second netw ork it is used 12 neurons in the input layer, 15 in the hidden one and 23 in the output layer. Here the 12 input neurons corresponds to the 12 elements used to code each character, while 10 and 23 neurons in the output layer corresponds to the 10 numbers and 23 letters, respectively that must be identified. Computer simulations determined the optimum number of neurones, in each hidden layer.

\subsection{Recognition Process}

The vehicle plate recognition process, show $\mathrm{n}$ in figure 2, consists of a plate position localization process that estimates the plate position inside the vehicle front or back side. Once the plate position is estimated, the vehicle plate characters are represented in a binary way, using only black and w hite, to segment the plate characters (number and letters). Those are subsequently coded and feed to the previously trained neural netw orks to carry out the recognition process of each plate symbol.

The localization process is a very important operation during the plate characters recognition process, because if the plate position cannot be accurately detected the recognition process becomes considerably more difficult and less accurate. The binarization, noise elimination and coding operations are the same carried out during the training process, then in this section only the plate localization and the vehicle plate character segmentation w ill be described.

\subsubsection{Vehicle Plate Localization Process}

In most vehicles of Mexico the plate is located in the middle-low er part of the vehicle, although itmay be different in several cases. The height of the plate from the ground varies depending on the vehicle model and in some cases the plate is located in the low er-left or low er-right part of the vehicle. Besides these variations of the plate position in the car, the distance betw een the camera and the vehicle may also varies, and then the localization of the plate inside the captured image plays a very important role. Because of that several vehicle plate localization methods have been proposed in the literature [3], [4], [10], although any of them has enough accuracy.

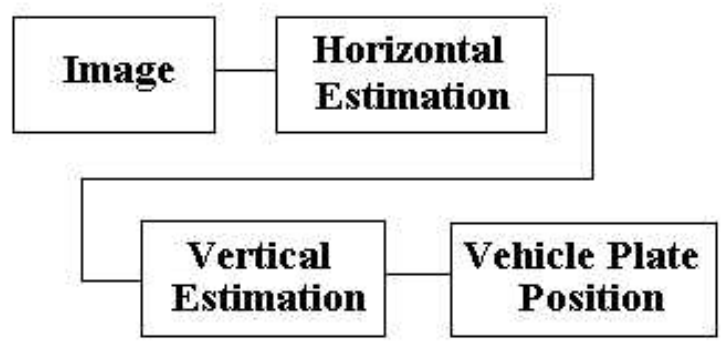

Figure 11. Vehicle plate localization process

To improve the vehicle plate localization accuracy, in this paper we proposed a new vehicle plate localization method using the properties of the captured image. This process, show $\mathrm{n}$ in figure 11, consists mainly of two processes: The horizontal and vertical plate localization. Those processes are based on the properties of the image where the plate is located since the plate image has properties that are not present in other parts of the car image. Figures 12 and 13 show s tw o captured images corresponding to the back side of tw o different vehicles and several lines corresponding totheintensity values of lines (a) to (f) in each image. 


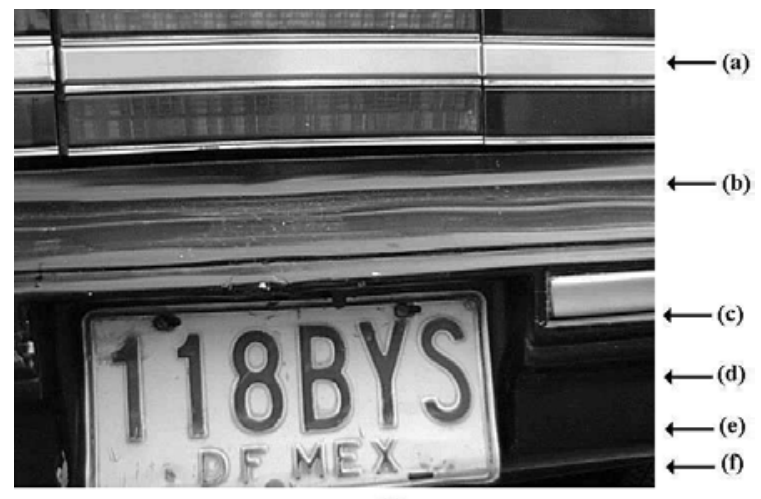

(a)

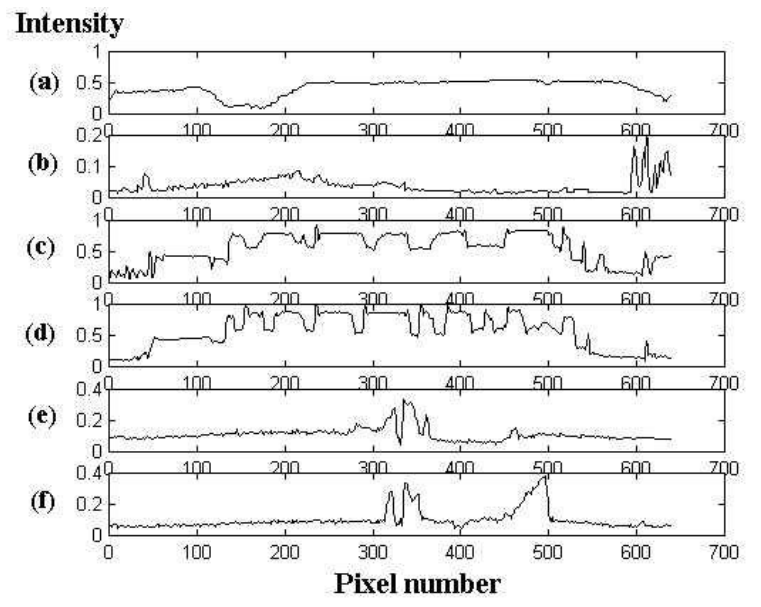

(b)

Figure 12. (a) Vehicle plate captured image, (b) Intensity values in each image line

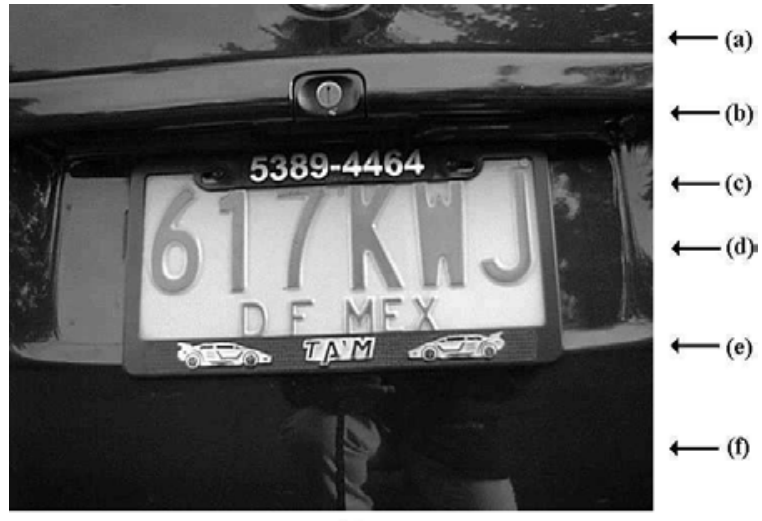

(a)

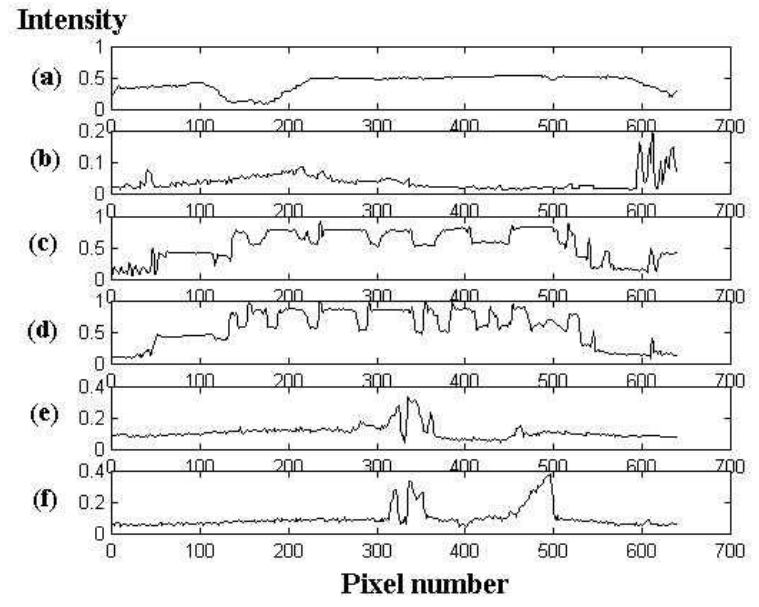

(b)

Figure 13. (a) Vehicle plate captured image, (b) Intensity values in each image line

As show $\mathrm{n}$ in figures 12 and 13, the intensity on the analysis lines (a) to (f) show some specialfeatures when they pass through numbers or letters, such as some picks $w$ ith similar $w$ idth representing letters or numbers. For instance in figure 12 the lines (c) and (d) that cross over the numbers and letters of the plate have quite similar intensity characteristics among them, while the intensity characteristics of ines (a) and (b) that cross over the back of the vehicle, and the lines (e) and (f) that cross over the letters 'D. F. MEX' is quite different to that of lines (c) and (d). Similar thing happens in figure $13 \mathrm{w}$ here the lines (a), (b), (e) and (f) cross over vehicle parts that not have number plates, w hile the lines (c) and (d) cross over numbers and letters of the vehicle plate. Thus it is possible to see that the intensity variations of lines crossing over letters and numbers of vehicle plates, lines (c) and (d) in figure 12 and lines (c) and (d) in figure 13, are quite similar among them. This fact suggests that the intensity properties of lines (a)(f) could be used to determine the horizontal and vertical plate position in the front as w ell as inthe back of vehicles. Thus, to determine the plate position w e can proceed as described below: 


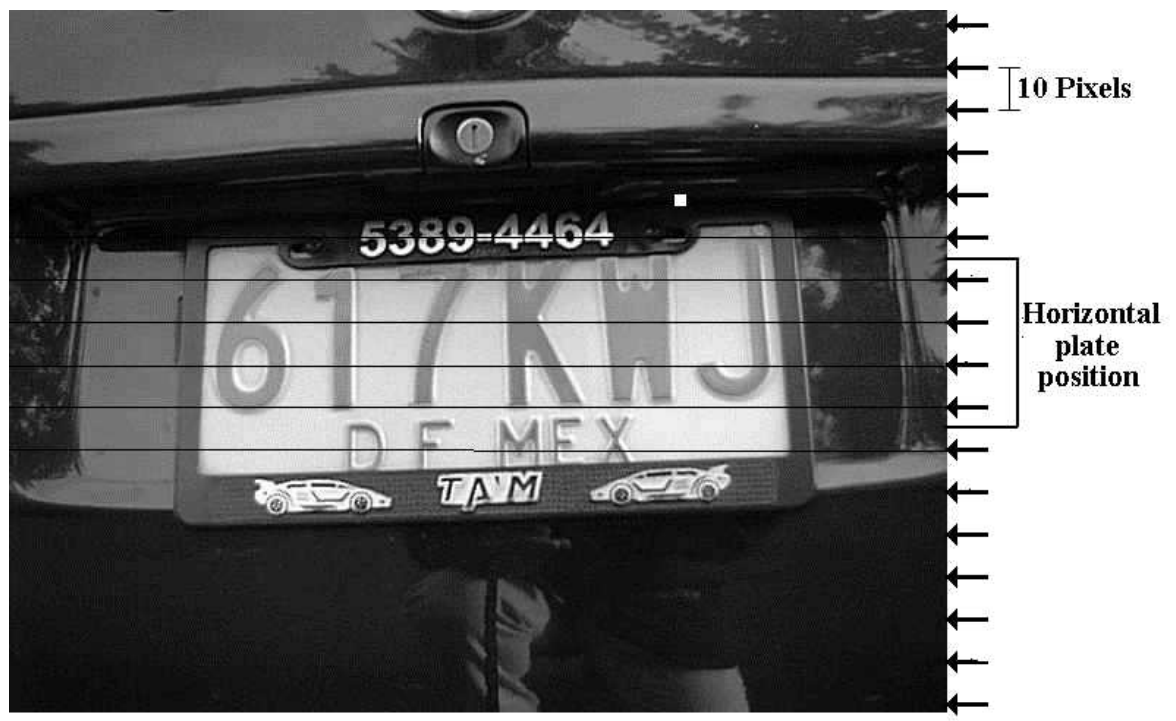

Figure 14. Estimation of matrix $B(n, k)$ used to fo horizontal plate position estimation. Upperboundaryline plus 5 pixels and lower boundary, line minus 5 pixels

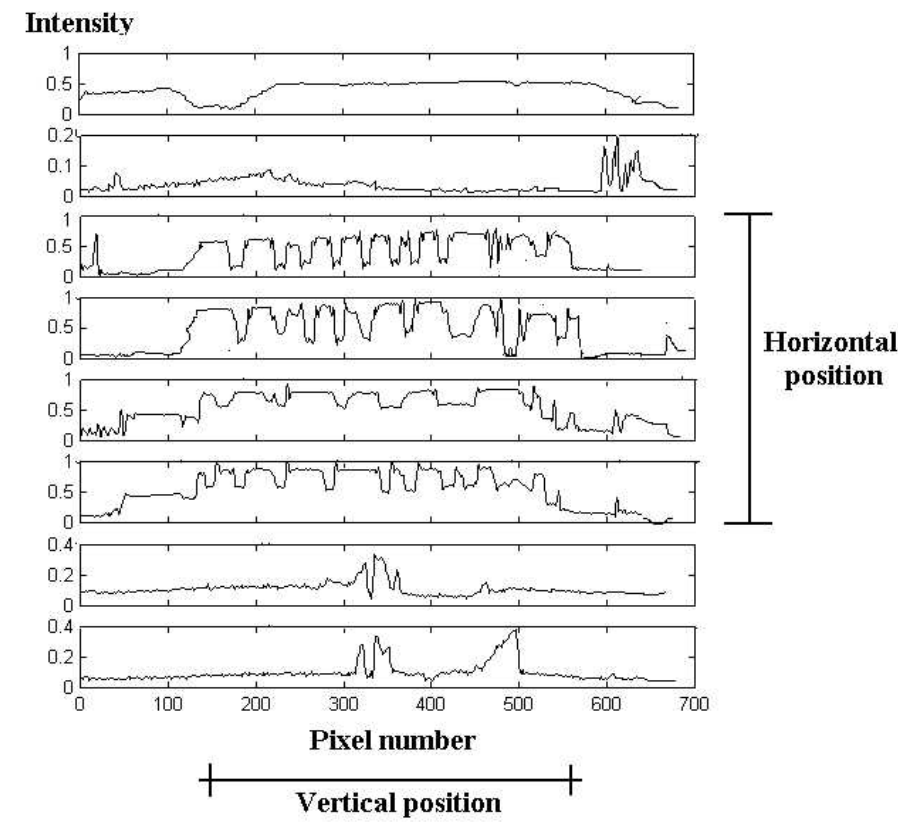

Figure 15. Upper and lower boundaries estimation using intensity lines.

Given an image represented in a matrix form, $0 \leq \mathbf{A}(j, k) \leq 1$, w here $\mathrm{j}=0,1, \ldots, \mathrm{J}-1$, and $\mathrm{k}=0,1, . ., \mathrm{K}-1$, define a new matrix as follow s (figure 14):

$$
\mathbf{B}(n, k)=\mathbf{A}(10 n, k), \quad \mathrm{n}=1,2, \ldots \mathrm{N},
$$

1. Estimate the number of crossing level of $\mathbf{B}(n, k), \mathbf{B}(n+1, k), \mathbf{B}(n+2, k)$ through 9 given levels, $r=0.1 \mathrm{~m}$ w here $m=1,2, . .9$. 
2. If the number of level crossing is larger than or equal to a given boundary, then $\mathbf{A}\left(10 n_{1}+5, k\right)$ is chosen as the low er plate boundary. Otherw ise increase $n$ by one, that is $n=n+1$, and go tostep 2 (Figure 15).

3. Once the plate upper boundary is determined, increase $n$ by one, that is $n=n+1$.

4. Estimate the number of crossing level of $\mathbf{B}(n, k), \mathbf{B}(n+1, k), \mathbf{B}(n+2, k)$ through 9 given levels, $r=0.1 \mathrm{~m}$ w here $m=1,2, . ., 9$.

5. If the number of level crossing is smaller than a given boundary, then $\mathbf{A}\left(10 n_{2}+5, k\right)$ is chosenas the upper plate boundary. Otherw ise increase $n$ by one, that is $n=n+1$, and go to step 5 .

6. Once the plate upper and low er boundaries are determined, we proceed to estimate the right and left boundaries. To this end define

$$
\mathbf{C}(m)=\mathbf{A}\left(10 n_{2}, m+100\right)
$$

7. Estimate the number of crossing level of $\mathbf{C}(m)$, through 9 given levels $r, r=0.1 \mathrm{j}$ w here $j=1,2, . ., 9$.

8. If the number of level crossings is larger than or equal to a given boundary, the estimated left plate boundary is given by $\mathbf{A}\left(10 n_{2}+5, m\right)$. Otherw ise do $m=m+1$ and go to point 8 .

9. Once the left boundary $w$ as estimated, we proceed to determine the right plate boundary. To this end do $m=m+1$.

10. Estimate the number of crossing level of $\mathbf{C}(m)$, through 9 given levels $r, r=0.1 j$ w here $j=1,2, . ., 9$.

11. If the number of level crossings is smaller than a given boundary, the estimated right plateboundary is given by $\mathbf{A}\left(10 n_{2}+5, m\right)$, and the plate position completely estimated. Otherw ise do $m=m+1$ and go to point 11 (Figure 15).

Figures 16 and 17 show some captured vehicle plate images and the plate localized images obtained using the proposed algorithm. These figures show that the proposed algorithm correctly estimates the vehicle plate position. The proposed system was evaluated using 310 pictures, most of them corresponding to vehicles back, as those images show $n$ in figures 12 and 13, w ith a correctly localzation average of $91.3 \%$ w hich is better than the performance of the system proposed in [3], [4] and [10].

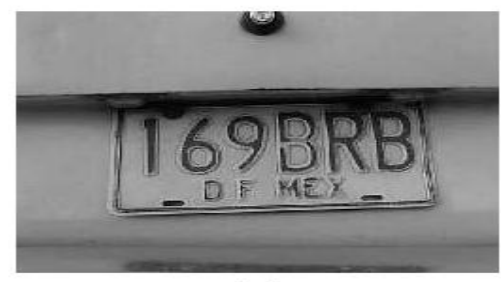

(a)

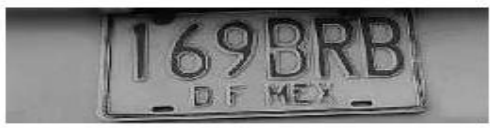

(b)

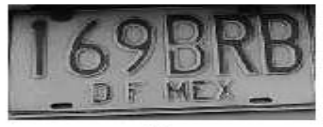

(c)

Figure 16. Vehicle plate position estimated using the proposed algorithm. a) Captured image, (b) Horizontal plate localization, (c) Localization process result. 


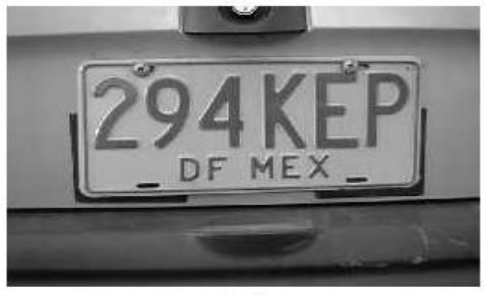

(a)

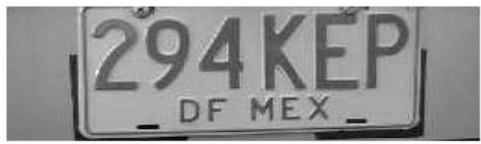

(b)

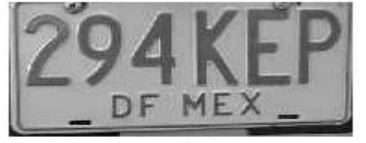

(c)

Figure 17. Vehicle plate position estimated using the proposed algorithm. a) Captured image, (b) Horizontal plate localization, (c) Localization process result.

\subsubsection{Segmentation}

After the plate position has been estimated, inside the captured car image, the part of the car image corresponding to the plate section is represented using only tw o intensity levels, zero (black) and one ( $w$ hite). That is the plate symbols are described using a binary representation form. Next, to extract the plate characters and then proceed to their identification, a labeling process is applied to the binary image, w hich is a very useful technique to segment characters with some inclination and differentsizes, because in this situation it is not possible to perform plate character segmentation using only vertical and horizontal lines. Thus, the labeling process allow s the segmentation of plate characters, independently of the plate inclination, position, size and distance between the camera and plate position. The segmentation process is show $\mathrm{n}$ in figure 18

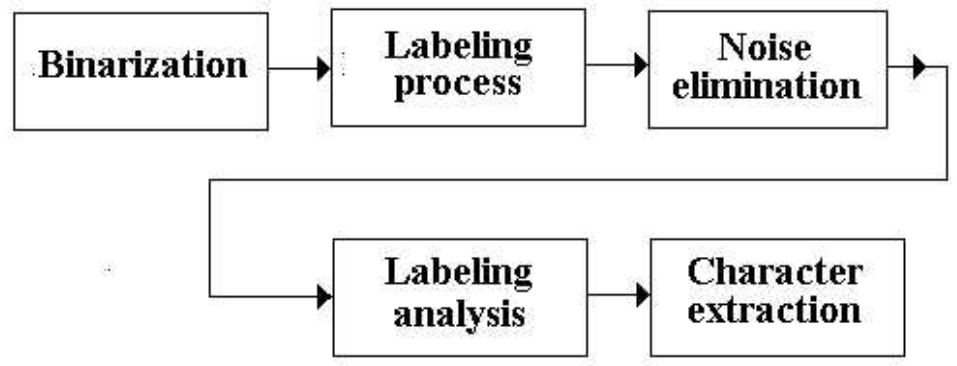

Figure 18. Segmentation process.

During the labeling process, a label is assigned to each plate symbol. How ever, in most cases, the plate border can be considered as a label as show $n$ in figure 19(c) leading to erroneous character segmentation. To avoid this problem all the labels corresponding to the segmented symbols are analyzed discarding the symbols that no corresponds to any of the plate symbols, letter or numbers, as show $\mathrm{n}$ in figure $19(\mathrm{~d})$. Finally, after the plate symbols have been segmented, these symbols are coded w ith a 12 elements vector derived from figure 9 , as it was done during the training process. 


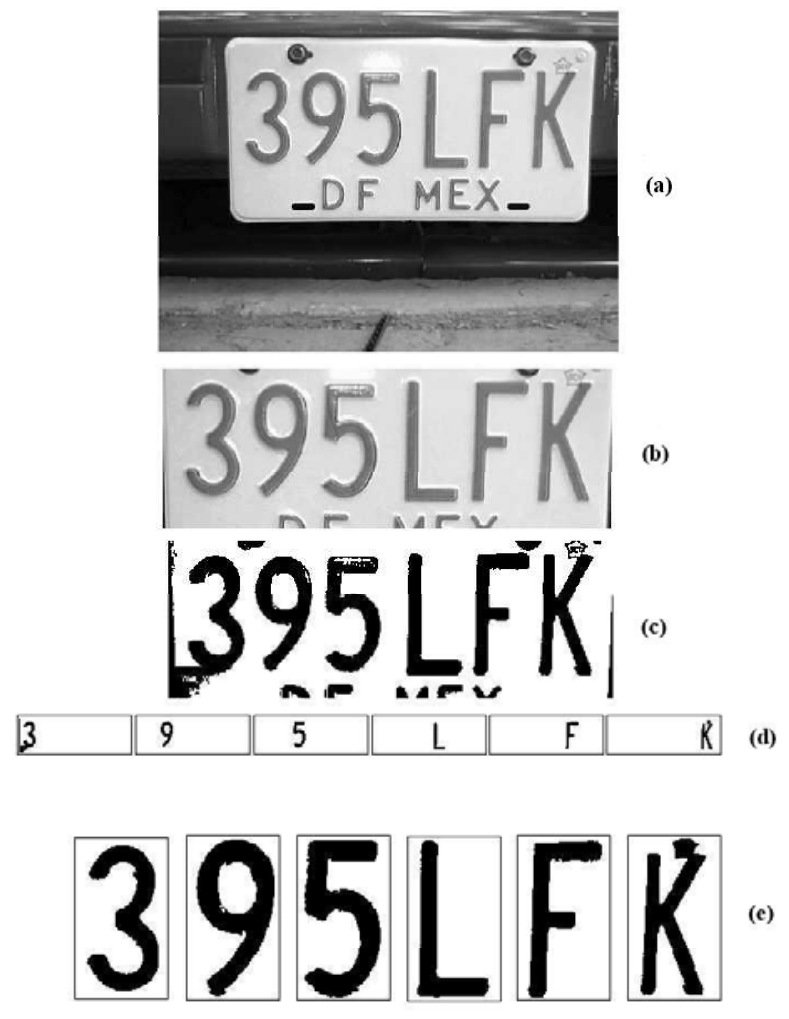

Figure 19. (a) Original image. (b) Automatically localized plate image, using the proposed method. (c) Binary representation of plate image shown in (b). (d) Labels corresponding to the symbols plate after the noise elimination process.(e) Segmented symbols.

\section{EVALUATION RESULTS.}

Two aspects w ere evaluated in the proposed system: The plate position estimation ability and the plate characters recognition rate. In both cases the system performance w as evaluated using 310 pictures, most of them corresponding to vehicles backsides, as those images show $n$ in figures 12 and 13 . $h$ the first case, that is the plate position estimation, a correctly localization average of $91.3 \% \mathrm{w}$ as obtained, which is better than other previously proposed systems [3], [4] and [10]. In the second case it was evaluated the system ability to recognize the segmented plate characters independently with a recognition rate of $95.5 \% \mathrm{w}$ hen the system $\mathrm{w}$ as required to recognize only digits, $91.6 \% \mathrm{w}$ hen itwas required to recognize only letters and $91.2 \% \mathrm{w}$ hen the system $w$ as required to recognize or identify a complete Mexico City number plate w hich consists of 3 digits and 3 letters. The proposed systemwas evaluated using MatLab in an SUN Workstation, as w ell as in a personal computer. Evaluation results show that the proposed systems performs fairly $w$ ell $w$ hen it is required to identify Vehicle plates obtained from vehicles images.

\section{CONCLUSIONS}

This paper proposed an automatic vehicle plate recognition system for applications such as the assistance in the detection and identification of stolen vehicles, access control to some exclusive places, etc. The proposed system consists mainly of two processes: The training process, in w hich a data based is build and the neural netw orks used for recognition are trained, and the recognition process which consists of a plate position estimation, segmentation, coding and plate character recognition stages. The system $w$ as evaluated using 310 pictures to determine it ability to estimate the plate position and the plate recognition performance. In the first case a correctly localization average of $91.3 \%$ w as obtained w hich improves other previously proposed plate localization systems [3], [4] and 
[10]. In the second case a recognition rate of $95.5 \% \mathrm{w}$ as obtained $\mathrm{w}$ ith only digits, $91.6 \% \mathrm{w}$ ith only letters and $91.2 \%$ w hen the system $w$ as required to recognize a Mexican plates consisting of 3 digits and 3 letters. Evaluation results show that the proposed systems performs fairly $w$ ell $w$ hen it is required to identify Vehicle plates obtained from image vehicles.

The proposed system w as developed mainly for identification of Mexico City vehicle plates, however with a few modifications it can also be used to identify plates from any Mexican State and even some other countries.

\section{ACKNOWLEDGEMENTS}

We thanks to Mr. Ricardo Arriaga Fuentes and Mr. Ricardo Aguayo Castallanos for their help to develop the plates database used in this research.

\section{REFERENCES}

[1] Web page: w w w .pgjdf.gob.mx

[2] Chutape, L. Li, and Xiaodong Q., Automatic License Number Extraction And Its Parallel Implementation, Proceeding of The $25^{\text {th }}$ Annual Conference of the IEEE, Industrial Eectronic Society, IECON'99, Volume 2, pag. 704-709, 1999.

[3] Zinino R. and Rovetta S., 1999 Visual Location Of License Plates by Vector Quantization, Proceedings of the1999 IEEE International Symposium on Circuits and Systems, ISCAS'99. Vol. 4, pag. 135-138.

[4] Zimic N., Ficzko J., Mraz M., Virant J., 1997 The Fuzzy Logic Approach to the Car Number Plate Locating Problem, Proceedings of Intelligent Information System, IIS'97, Pag. 227-230.

[5] Coetzee C., Botha C. and Weber D. 1998 PC Based Number Plate Recognition System, Proceedings of IEEE International Symposium on Industrial Electronics, ISIE98, Vol.2, Pag. 605610.

[6] Raus M., Kreft L., 1995 Reading Car License Plates by the Use of Artificial Neural Netw ork, Proceedings of The $38^{\text {th }}$ Midw est Symposium on Circuits and Systems, Proceedings, Vol.1, Pag. 538-541.

[7] Maged M. Fahmy M., 1994 Automatic Number-Plate Refcognition: Neural Netw ork Approach, Proceedings of Vehicle Navigation and Information Systems Conference, Pag. 99-101.

[8] de Vena L., 1993 Number Plate Recognition by Hierarchical Neural Netw ork, Proceedings of 1993 International Joint Conference on Neural Netw ork, Vol.3, Pag. 2106-2108.

[9] Gendy S., Smith C. L., and Lachow icz S., 1997 Automatic Car Registration Plate Recognition Using Fast Hough Transform, Proceedings of International Carnahan Conference on Security Technology, Pag. 209-218.

[10] He M. G., Harvey A. L., Vinay T., 1996 Hough Transform in Car Number Plate Skew Detection, Proceedings of Fourth International Sympsium on Signal Processing and Its Application, ISSPA 96,Vol. 2, Pag. 593-596.

[11] Garris M.D., Wilson C.L., Blue J. L., 1998 Neural Netw ork-Based Systems for Handprint OCR applications, IEEE Transaction on Image Processing Vol. 8, No. 8, pag. 1097-1112.

[12] Mori S., Suen C.Y., Yamamoto K., 1992 Historical Review of OCR Research and Development, Proceedings of the IEEE Vo. 80, No. 7, pag. 1029-1058. 
Authors Biography

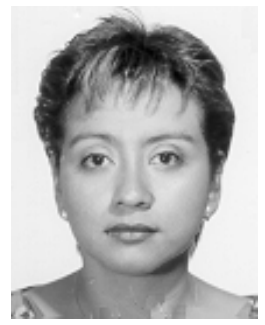

Noemi Vázquez Tecpanecatl

Received the Bachelor and Master Degrees from the ESIME Culhuacan of the National Polytechnic Institute of Mexico in 1995 and 2002 respectively. In march 1997 she joint the Nutritional Department of the Oncology Hospital of the Medical Centre XXI Century, of the "Instituto Mexicano del Seguro Social" where she is now an Engineers. In August 2000 she also joint the Computer Department of the ESME Culhuacan of the National Polytechnic Institute w here she is now a lecturer. Her research interests are in the Pattern recognition field.

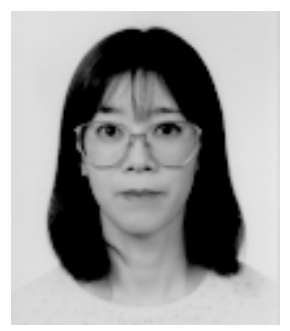

Mariko Nakano Miyatake (PhD).

She received a M.E. degree in Electrical Engineering from the University of Electro-Communications, Tokyo Japan in 1985, and her Ph. D in Electrical Engineering from The Universidad Autonoma Metropolitana (UAM), Mexico City, in 1998. From 1985 to December 1986, she was with Toshiba Corporation, Kaw asaki Japan. From January 1987 to March 1992, she w as w ith Kokusai DataSystems Inc., Tokyo, Japan. From July 1992 to February 1997 she w as a Department of Eectrical Engineering of the UAM Mexico. In February 1997, she joined the Graduate Department of The Mechanical and Electrical Engineering School of The National Polytechnic Institute of Mexico, where she is now a Professor. In 1999 received the Research Aw ard from the National Polytechnic Institute. Her research interests are in adaptive systems, neural netw orks, pattern recognition and related field. She is a member of the RISP and the National Research System of Mexico. mariko@calmecac.esimecu.ipn.mx

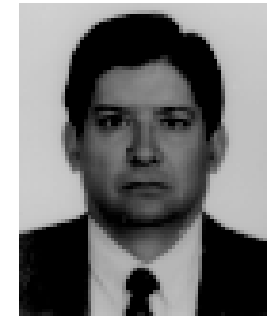

Héctor Perez-Meana (PhD)

He received a M.E. degree in Eectrical Engineering from The University of Electro-Communications, Tokyo, Japan, in 1986, and $\mathrm{PhD}$ in Eectrical Engineering from Tokyo Institute of Technology, Japan, in 1989. From 1982 to 1997, he w as a professor in the Electrical Engineering Department of The UAM, Mexico City. In February 1997, he joined the Graduate Department of The Mechanical and Electrical 
Engineering School on the National Polytechnic Institute of Mexico, where he is now a Professor and Chair of The PhD Program on Electronics and Communications. From March 1989 to September 1991, he $w$ as a visiting researcher at Fujitsu Laboratories Ltd, Kaw asaki, Japan. In 1991 he received the ECE excellent Paper Aw ard in Tokyo Japan, and in 1999 the Research Aw ard from the National Polytechnic Institute. His principal research interests are adaptive processing, pattern recognition and relatedfields. $\mathrm{He}$ is a member of the IEEE, IEICE. hmpm@calmecac.esimecu.ipn.mx. 